\title{
Factors associated with early menarche: results from the French Health Behaviour in School-aged Children (HBSC) study
}

\author{
Adrien Gaudineau ${ }^{1,2^{*}}$, Virginie Ehlinger ${ }^{1}$, Christophe Vayssiere ${ }^{1,3}$, Beatrice Jouret ${ }^{1,4}$, Catherine Arnaud ${ }^{1,5}$, \\ Emmanuelle Godeau ${ }^{1,6}$
}

\begin{abstract}
Background: Puberty is a transition period making physiological development a challenge adolescents have to face. Early pubertal development could be associated with higher risks of poor health. Our objective was to examine risk behaviours, physical and psychological determinants associated with early menarche ( $<11$ years).

Methods: Early menarche was assessed in the Health Behaviour in School-aged Children French cross-sectional survey. Data were collected in 2006 by anonymous self-reported standardized questionnaire from a nationally representative sample of 107215 years old girls in school classrooms. Family environment, school experience, physical and psychological factors, risk behaviours (substance use and sexual initiation) were recorded. Logistic regression models were applied (analysing for crude and adjusted relationships between early menarche and risk behaviours controlled for family context).
\end{abstract}

Results: Median age at menarche was 13.0 years; 57 girls (5.3\%) were early-matured. Controlled for familial environment, early menarche was associated with having had more than two life-drunkenness episodes (adjusted $\mathrm{OR}=2.5$ [1.3-4.6]), early sexual initiation (adjusted $\mathrm{OR}=2.8$ [1.3-6.0]) and overweight (adjusted $\mathrm{OR}=7.3$ [3.6-14.9]).

Conclusion: Early-maturing girls may affiliate with older adolescents, hence engage in risk behaviours linked to their appearance rather than their maturity level. Factors associated with early menarche highlight the need to focus attention on early-matured girls to prevent further health problems linked to risk behaviours.

\section{Background}

Adolescence is a transition period from childhood to adult life during which pubertal development and sexual maturation take place. During puberty, hormonal, psychological, cognitive and physical changes occur simultaneously and interactively making physiological development a challenge adolescents have to face, with emotional, social and behavioural dimensions. A feature of sexual maturation in the human race is the 4 to 5 years physiological variation of pubertal age observed in normal individuals living in the same conditions [1]. This variability is mainly due to genetic, ethnic, environmental and nutritional factors [2]. Considering girls, age variations of menarche may be important: previous studies have shown that $5 \%$ of the population reported

\footnotetext{
* Correspondence: a.gaudineau@orange.fr

'UMR Inserm U558/University Paul Sabatier, Toulouse, France
}

ages at onset before 10 or after 15 years [3]. Therefore, within a same biological age, variability exists not only in adolescent's physical appearances directly linked to hormonal effects, but more widely in their behaviours. Previous research has described that girls feeling "ontime" regarding their puberty had the most positive feelings in terms of pubertal development [4]. Therefore, in agreement with some authors [5], anomalies in pubertal timing (early or delayed pubertal development) could be associated with higher risks of poor health. Early pubertal development is of particular medical interest in terms of care management and prevention implications. Previous studies on factors associated with early pubertal development have focused their attention on one specific aspect of health only (whether in terms of family environment, physical or psychological factors or risk behaviours) despite the fact that all those factors interact 
to define global health as given by the World Health Organization (WHO).

The objective of this paper is to examine multiple factors (school experience, physical or psychological factors and risk behaviours) associated with early menarche in a large national representative sample of schoolgirls, using the French data from the 2006 Health Behaviour in School-aged Children (HSBC) international study.

\section{Methods}

Data were obtained from the HBSC international WHO collaborative cross sectional study [6], carried out every four years since 1982. This survey aims to better understand health, well-being, health behaviours and social conditions of school children aged 11, 13 and 15 years and to examine self-perceived determinants of health. Records allow not only to examine the trend of health's indicators but also to initiate prevention strategies to promote youth's health. France has participated in 2006 for the fourth time [7], along with 40 other countries or regions sharing a common protocol and using the international standardized questionnaire [8] available in all the participating countries.

The French HBSC 2006 population included 7154 pupils ( 3558 boys and 3596 girls) from the 8th to the 13th grade, sampled in public or private schools (school and pupils participation rates: 79.1 and $81.1 \%$, respectively). Sampling strategy consisted in a stratified random design (stratification in four categories of school settings and seven educational levels) clustered into schools and classrooms. Because some risk behaviour variables were only asked of the oldest group (drugs consumption, sexual initiation), analyses were restricted to the 15 year-old girls $(n=1072)$. We defined early menarche as a reported onset of menarche before 11 years. Depending on studies, early menarche is defined from 9 to 11.5 years [9-11]. This variability, though important, is explained by its relation with the distribution of the age at onset of menarche in the studied populations. Therefore, age limits to define early menarche are neither definitive nor universal. In this study, we hypothesized that anomalies in pubertal timing could be defined using the $5^{\text {th }}$ percentile of the observed distribution of age at menarche in our population.

The self anonymous classroom-administered questionnaire was developed by the HBSC international research network. All items were piloted and pre-tested at international and national levels prior to the main survey [12-15]. Parental consent was assessed. At students' level, participation in the survey was voluntary, with assurances provided in relation to confidentiality and anonymity. Age at menarche was derived from the following question: "Have you already had your periods?" with possible answers: "No, I haven't yet"/"Yes, I have at the age of: (year, month)".

Various factors associated to early menarche asked in the HBSC survey (family environment, school experience, physical and psychological factors, risk behaviours) were included in the analyses in accordance to the literature $[6,16,17]$ and to our initial hypothesis that more mature physical appearance at the same biological age may be associated with higher risks of poor physical and psychological health and higher frequency of risk behaviours. Family environment variables were: family structure with response options of "traditional" (living with both biological father and mother) and "other family structure"; parental employment with "at least one parent working" and "none"; socio-economic status assessed by the Family Affluence Scale (FAS) [18] with "medium to high" and "low". School experience variables were: school results with "average to higher" and "below average"; liking school with "yes" and "no"; peers acceptance with "high" and "low". Risk behaviours variables were: daily smoking with "no" and "yes"; life drunkenness episodes with " $<2$ " and " $\geq 2$ "; life cannabis use with " $<3$ episodes" and " $\geq 3$ episodes"; sexual initiation before 15 years (colloquial terminology such as "having sex" or "going all the way" was added to ensure that respondents understood the question asked about full penetrative sex) with "no or not yet" and "yes". Physical and psychological factors included: Body Mass Index (BMI) (calculated from self-reported height and weight) with "normal or thin" and "overweight or obese". as recommended by the International Obesity Task Force [19]; body image perception with "normal or thin" and "overweight"; diet use with "no" and "yes"; self-rated health with "good" and "bad"; life assessment from the Cantril scale [20] with "high" and "low"; recurrent health complaints [6] (defined as two symptoms or more at least once a week, from which depression, irritability, nervousness, headaches, stomach-aches, back-aches, dizziness and sleeping troubles) with "no" and "yes".

Because pubertal development was not achieved in all girls taking part in the study, survival analysis methods were used to estimate the distribution of age at menarche (Kaplan-Meier). Mean and standard deviation (SD) was also reported in the 15 year-old girls who had already experienced menarche in order to compare our data to other studies. We compared frequencies of exposition to each predefined variables according to menarche status (early versus others) using a $\chi^{2}$ test and a Fisher's exact test where needed. We then performed a multivariable logistic regression analysis to determine factors associated with early menarche. School experience, risk behaviours, physical and psychological factors were included in the initial model as covariates if they were related to early menarche at a $20 \%$ significance 
level in the univariate analysis. A backward procedure was then used to remove variables from the model $(1 \%$ significance level), adjusting for familial environment characteristics. Regressions excluded girls who had missing values on any of the variables considered in the initial model. The final model was rerun using all available observations to check stability. All the analyses took into account the sampling strategy, setting classes as primary sampling units. Adjusted and unadjusted odds ratios (ORs) and 95\% confidence intervals (CIs) are reported. All analyses were performed using STATA statistical package (STATA v9.0 College Station, TX) [21] and took into account the sampling strategy.

The study protocol was approved by the Ministry of Education and the French National Commission of Computer Science and Freedom, as the national review board for surveys involving people and data management.

\section{Results}

Median and mean age at menarche were 13.0 years (interquartile range (IQR) 12.0-13.8) and 12.8 years (SD 1.2) respectively. In total 57 girls were considered earlymatured (5.3\% in our 15 year-old population).

Factors associated with early menarche are shown in table 1. Frequency of girls living in a non-traditional family structure was significantly greater among earlymatured girls than among others (45.6\% versus $27.1 \%$ ), as well as frequencies of low peers acceptance $(42.1 \%$ versus $25.3 \%$ ), having had more than two life drunkenness episodes (36.4\% versus $17.6 \%)$, early sexual initiation $(28.9 \%$ versus $11.1 \%)$, poor health perception (35.1\% versus $20.2 \%)$, recurrent health complaints (71.9\% versus $51.7 \%)$. Frequencies of girls either overweight according to self-reported BMI $(29.1 \%$ versus $7.0 \%)$ or with an overweight body image (63.2\% versus $42.9 \%)$, and weight loss diet use (31.6\% versus $17.9 \%)$ were again higher among early-matured girls than among others.

The final multivariate model showed that having had more than two life drunkenness episodes, a sexual initiation before 15 years and being overweighted or obese remained significantly and independently associated with early menarche $(\mathrm{p}<0.01)$, after controlling for familial environment (i.e. family structure, parental employment and FAS) (table 2).

\section{Discussion}

Age at menarche has largely decreased in most developed countries and seems stabilised at 13 years with 0.5 years variations between countries [22]. Our results are in line with this trend. According to some research [23], decrease in mean age of menarche could be associated with a decrease in its variability (as measured by standard deviation). With 1.2 years, our standard deviation is narrower than in previous studies on the same population. Since girls with an early menarche belong to a deviant category from peers, even more when age at onset is homogeneous [5], our finding is important because of its potential impact on early-matured girls' behaviours.

From our results, after controlling for familial environment, to have had more than two life drunkenness episodes, a sexual initiation before 15 years and selfreported overweight or obesity remained the only factors significantly and independently associated with early menarche $(\mathrm{p}<0.01)$. Health risk behaviours are major contributors to morbidity and mortality among adolescents [24]. Although initiation of some of these behaviours in middle or late adolescence may reflect psychologically healthy experimentation [25], adolescents who initiate health risk behaviours at an early age appear to be at greater risk for negative consequences later in life [26]. The mediating mechanisms at stake to understand the association between risk behaviours and early menarche is still debated in the literature. According to some authors, early pubertal development could result in affiliation with older adolescents, who often experience increased deviance and substance use [27]. Therefore, affiliation with an older peer group putatively increases the risk for initiation and addiction because of greater availability of substances, peer modelling of use and biased perceptions of substance use norms. Earlymatured girls may therefore face pressure to engage in behaviours appropriate to their appearance rather than their experience, coping or cognitive abilities [28]. For others, early pubertal development could lead to depression and more frequent risk behaviours $[11,17,24,28]$. From our results, we cannot conclude on this hypothesis: though the association of lower peer acceptance with early menarche is significant in univariate analysis (table 1), the cross-sectional methodology with self-perceived determinants of health is submitted to various biases.

In Stice et al's prospective study of 496 girls [11], early menarche (defined as an age at onset of menarche before 11.6 years) was associated with increased substance use and abuse (defined as two or more impairments of role obligations directly resulting from substance use). Although in line with this association, our results showed that among all substance use variables tested (tobacco, cannabis, alcohol), only to have had two or more life drunkenness episodes was associated with early menarche (adjusted OR $=2.595 \% \mathrm{CI}$ [1.3-4.6]).

Drunkenness is an indicator of alcohol misuse. Frequent or heavy alcohol users report poorer subjective and overall health and a greater number of overnight 
Table 1 Factors associated to early menarche in 1072 girls aged 15 years. Univariate analysis

\begin{tabular}{|c|c|c|c|c|}
\hline & $\begin{array}{r}\text { Early menarche } \\
(\mathrm{N}=57) \\
\mathrm{n}(\%)\end{array}$ & $\begin{array}{r}\text { Menarche } \geq 11 \mathrm{y} . \\
(\mathrm{N}=1015) \\
\mathrm{n}(\%)\end{array}$ & OR $(95 \% \mathrm{Cl})$ & p value* \\
\hline \multicolumn{5}{|l|}{ Familial environment } \\
\hline \multicolumn{5}{|l|}{ Family structure } \\
\hline traditional & $31(54.4)$ & $739(72.9)$ & 1 & 0.004 \\
\hline other family structure & $26(45.6)$ & $275(27.1)$ & $2.3(1.3-3.9)$ & \\
\hline \multicolumn{5}{|l|}{ Parental employment } \\
\hline at least one parent working & $54(94.7)$ & 937 (92.9) & 1 & 0.590 \\
\hline none & $3(5.3)$ & $72(7.1)$ & $1.4(0.4-4.5)$ & \\
\hline \multicolumn{5}{|l|}{ FAS } \\
\hline medium to high & $43(76.8)$ & $881(87.4)$ & 1 & 0.026 \\
\hline low & $13(23.2)$ & $127(12.6)$ & $2.1(1.1-4.0)$ & \\
\hline \multicolumn{5}{|l|}{ School experience } \\
\hline \multicolumn{5}{|l|}{ School results } \\
\hline average to higher & $42(73.7)$ & $815(80.6)$ & 1 & 0.186 \\
\hline below average & $15(26.3)$ & $196(19.4)$ & $1.5(0.8-2.7)$ & \\
\hline \multicolumn{5}{|l|}{ Liking school } \\
\hline yes & $32(58.2)$ & $605(59.8)$ & 1 & 0.812 \\
\hline no & $23(41.8)$ & $407(40.2)$ & $1.1(0.6-1.9)$ & \\
\hline \multicolumn{5}{|l|}{ Peers acceptance } \\
\hline high & $33(57.9)$ & $754(74.7)$ & 1 & 0.008 \\
\hline low & $24(42.1)$ & $255(25.3)$ & $2.2(1.2-3.8)$ & \\
\hline \multicolumn{5}{|l|}{ Risk behaviours } \\
\hline \multicolumn{5}{|l|}{ Daily smoking } \\
\hline no & $39(76.5)$ & $816(84.0)$ & 1 & 0.139 \\
\hline yes & $12(23.5)$ & $155(16.0)$ & $1.6(0.9-3.1)$ & \\
\hline \multicolumn{5}{|l|}{ Life drunkenness episodes } \\
\hline$<2$ & $35(63.6)$ & $810(82.4)$ & 1 & 0.001 \\
\hline$\geq 2$ & $20(36.4)$ & $173(17.6)$ & $2.7(1.5-4.6)$ & \\
\hline \multicolumn{5}{|l|}{ Life cannabis use } \\
\hline$<3$ episodes & $44(78.6)$ & $852(86.5)$ & 1 & 0.108 \\
\hline$\geq 3$ episodes & $12(21.4)$ & $133(13.5)$ & $1.8(0.9-3.5)$ & \\
\hline \multicolumn{5}{|l|}{ Sexual initiation $<15$ years } \\
\hline no or not yet & $37(71.1)$ & $856(88.9)$ & 1 & 0.001 \\
\hline yes & $15(28.9)$ & $107(11.1)$ & $3.2(1.7-6.3)$ & \\
\hline \multicolumn{5}{|l|}{ Physical and psychological factors } \\
\hline \multicolumn{5}{|l|}{ Self-reported BMI } \\
\hline normal or thin & $39(70.9)$ & $911(93.0)$ & 1 & $<0.001$ \\
\hline overweight or obese & $16(29.1)$ & $68(7.0)$ & $5.5(2.9-10.6)$ & \\
\hline \multicolumn{5}{|l|}{ Body image } \\
\hline normal or thin & $21(36.8)$ & $579(57.1)$ & 1 & 0.004 \\
\hline overweight or obese & $36(63.2)$ & $435(42.9)$ & $2.3(1.3-4.0)$ & \\
\hline \multicolumn{5}{|l|}{ Diet use } \\
\hline no & $39(68.4)$ & $825(82.1)$ & 1 & 0.023 \\
\hline yes & 18 (31.6) & $180(17.9)$ & $2.1(1.1-4.0)$ & \\
\hline \multicolumn{5}{|l|}{ Self-rated health } \\
\hline good & $37(64.9)$ & 807 (79.8) & 1 & 0.011 \\
\hline bad & $20(35.1)$ & $204(20.2)$ & $2.1(1.2-3.8)$ & \\
\hline \multicolumn{5}{|l|}{ Life assessment } \\
\hline high & 39 (68.4) & 781 (77.4) & 1 & 0.137 \\
\hline low & 18 (31.6) & $228(22.6)$ & $1.6(0.9-2.9)$ & \\
\hline
\end{tabular}


Table 1: Factors associated to early menarche in $\mathbf{1} 072$ girls aged 15 years. Univariate analysis (Continued)

\begin{tabular}{llll}
\hline $\begin{array}{l}\text { Recurrent health complaints } \\
\text { no }\end{array}$ & $16(28.1)$ & $489(48.3)$ & 1 0.005 \\
yes & $41(71.9)$ & $524(51.7)$ & $2.4(1.3-4.4)$ \\
\hline
\end{tabular}

Abbreviations: FAS = Family Affluence Scale; BMI = Body Mass Index; OR = Odds Ratio; Cl = Confidence Interval

${ }^{*} \chi^{2}$-test or Fisher's exact test where necessary

All analysis took into account the sampling strategy

Table 2 Factors associated to early menarche in $\mathbf{9 5 6}$ girls aged 15 years. Multivariable logistic regression analysis

\begin{tabular}{|c|c|c|c|}
\hline & & $\begin{array}{r}\text { Adjusted OR } \\
(95 \% \mathrm{Cl})\end{array}$ & $p$-value \\
\hline $\begin{array}{l}\text { Life drunkenness } \\
\text { episodes }\end{array}$ & $\geq 2$ & $2.5(1.3-4.6)$ & 0.006 \\
\hline Sexual initiation & $<15$ years & $2.8(1.3-6.0)$ & 0.007 \\
\hline BMI & $\begin{array}{l}\text { overweight or } \\
\text { obese }\end{array}$ & $7.3(3.6-14.9)$ & $<0.001$ \\
\hline
\end{tabular}

Abbreviations: FAS = Family Affluence Scale; BMI = Body Mass Index; OR = Odds Ratio; $\mathrm{Cl}=$ Confidence Interval

All analysis took into account the sampling strategy and controlled for familial environment (family structure, parental employment, FAS).

hospital stays than infrequent or non users [29]. There is a strong association between adolescent alcohol misuse and an array of other behaviours or conditions, such as smoking and illegal drug use, risky sexual behaviour, disruptive behaviour, depressive and anxiety disorders, eating disorders and obesity [29]. There is evidence that these behaviours cluster in young people with high-risk lifestyles [29]. The association we found could in fact be even stronger than shown because based on self-perceived determinants of health, leading to a risk of understatement although our questionnaire was validated from previous HBSC studies in the same context, and the lack of power of our analysis (by definition, early menarche was rare).

The second type of risk behaviour included in our model and significantly associated with early menarche was early sexual intercourse (defined as ever having had sexual intercourse before 15 years). A 3-4 years decrease of age at first intercourse was observed in Western countries during the last half of the $\mathrm{XX}^{\text {th }}$ century [30]. Early sexual initiation could have negative effects on health due to the developmental inabilities to deal with consequences of such sexual activity. Studies have shown that it was associated with a lesser use of contraceptive methods and an increase in sexual transmitted diseases exposure [31].

Furthermore, several research findings suggest that early sexual activity more likely reflects problems in adolescent development than successful rite of passage [32]: thus it has been found associated with other risk behaviours such as smoking tobacco, higher levels of drunkenness and cannabis use and frequent evenings out with friends [33]. In addition, early sexual initiation has been associated with poorer health-related quality of life among girls [33]. In our study, sexual initiation before 15 years was about three times more frequent for early-matured girls compared to others (adjusted OR $=2.895 \%$ CI [1.3-6.0]).

Even if our study was cross-sectional by design, we can hypothesise that those two risk behaviours are probably consequences of early menarche (only one girl had sexual intercourse and three had been drunk more than twice before 11 years).

Potential physical influences of age at menarche include factors such as weight, nutrition and exercise [34]. The World Health Organization recognizes that childhood overweight and obesity have reached epidemic proportions in most industrialized countries. BMI is associated with direct measures of fatness, cardiovascular risk factors, social and psychological problems and with poor general health-related quality of life [35]. A high BMI during childhood and adolescence is associated with an increased risk of adult obesity [35] and premature mortality [36]. In our study and as hypothesized, self-reported overweight or obesity remained strongly associated with early menarche (adjusted OR = 7.3 95\%CI [3.6-14.9]). However, due to the cross-sectional design of our study, direction of this association cannot be known. In the literature, this question is still debated [37]: on the one hand, girls who mature early tend to be more frequently obese as adults (oestrogens promoting deposition of fat in peripheral adipose tissue) [38]; on the other, childhood BMI is associated with an earlier menarche (due to oestrogens' production by peripheral adipose tissue). These findings support the need to explore such associations in longitudinal studies.

To eliminate potential biases, we controlled our results for familial environment factors because individual differences in the timing of pubertal maturation are influenced by both genes and environment. According to Belsky et al [16], early development may be environmentally triggered and may actually be an adaptive response to a stressful environment (marital conflict, father absence, poor parenting or low socio-economic status). Though controversial, the Belsky et al.'s theory has been supported by other studies [17]. A potential limitation of our study lies in our choice of pubertal development estimate: the first manifestation of puberty 
is the development of the mammal gland. Menarche appears 2 to 2.5 years after the beginning of puberty, but timing is shortened in the case of late puberty. However, age at menarche, because easy to determine and to memorise, serves as an estimate in many studies [39]. Information on age at menarche is often retrospectively identified in most studies [40], hypothesising that menarche is a memorable event in a woman's life. Previous studies have shown a good correlation between stated and real age at menarche within a 4-year-recall period [40]. Because in our study, girl's ages range from 14.6 to 16.4 years, we made the assumption that the memory bias could be neglected.

\section{Conclusions}

In conclusion, our results add to a growing literature [41] that suggests that girls who experienced early menarche are more likely to engage in risk behaviours such as alcohol abuse and early sexual initiation. These results highlight the need for more awareness and more prevention information in the case of early menarche and the overall need to reinforce prevention around puberty. More research is needed to better understand the associations between risk behaviours and early menarche on larger populations from collaborative studies, and furthermore on how obesity interacts with early menarche and risk behaviours.

\section{Acknowledgements}

HBSC is an international study carried out in collaboration with WHO/EURO. The international coordinator of the 2005-2006 study was Candace Currie, University of Edinburgh, Scotland; and the data bank manager was Oddrun Samdal, University of Bergen, Norway. A complete list of the participating researchers can be found on the HBSC website http://www. HBSC.org. The 2006 HBSC study in France was led by the Ministry of education (Rectorat de Toulouse) with INSERM U558 and funded by INPES, OFDT and Caisse nationale RSI.

\section{Author details \\ ${ }^{1}$ UMR Inserm U558/University Paul Sabatier, Toulouse, France. ${ }^{2} \mathrm{CHU}$ Hautepierre/University Louis Pasteur, Strasbourg, France. ${ }^{3}$ Maternity Paule de Viguier/University hospital, Toulouse, France. ${ }^{4}$ Pediatric endocrinology departement/University hospital, Toulouse, France. ${ }^{5}$ Clinical epidemiology departement/University hospital, Toulouse, France. ${ }^{6}$ Service Médical du Rectorat, Toulouse, France.}

\section{Authors' contributions}

AG analysed the data and wrote the manuscript. VE contributed to the analysis. CV \& BJ have made substantial contributions to interpretation of data. CA \& EG conceived of the study, contributed to the analysis and cowrote the manuscript. All Authors read and approved the final manuscript.

\section{Competing interests}

The authors declare that they have no competing interests.

Received: 21 December 2009 Accepted: 30 March 2010 Published: 30 March 2010

\section{References}

1. Tanner JM: Growth at adolescence Oxford: Black-well 1962.

2. Kaprio J, Rimpelä A, Winter T, Viken RJ, Rimpelä M, Rose MJ: Common genetic influences on BMI and age at menarche. Hum Biol 1995, 67:739-753.

3. Ailbereisen RK, Kracke B: Self-reported maturational timing and adaptation in adolescence. Health risks and developmental transitions during adolescence Cambridge, Cambridge University PressSchulenberg J, Maggs JL, Hurrelmann K 1997, 85-109.

4. Dubas JS, Graber JA, Petersen AC: A longitudinal investigation of adolescents' changing perceptions of pubertal timing. Developmental psychiatry 1991, 27:580-586.

5. Caspi A, Moffitt TE: Individual differences are accentuated during periods of social change: the sample case of girls at puberty. Journal of personality and social psychology 1991, 61:157-168.

6. Currie C, Gabhainn SN, Godeau E, Roberts C, Smith R, Currie D, Picket W, Richter M, Morgan A, Barnekow V: Inequalities in young people's health: Health Behaviour in School-aged Children international report from the 2005/ 2006 survey Copenhagen, Denmark: World Health Organization 2008.

7. Godeau E, Arnaud C, Navarro F: La santé des élèves de 11 à 15 ans en France/2006 - Données françaises de l'enquête internationale Health Behaviour in School-aged Children (HBSC). [Health of 11-15 year-old students in Francel 2006 French data form the international Health Behaviour in School-aged Children (HBSC) survey] Paris, France: Editions INPES 2008, French.

8. Roberts C, Currie C, Samdal O, Currie D, Smith R, Maes L: Measuring the health and health behaviours of adolescents through cross-national survey research: recent developments in the Health Behaviour in School-aged Children (HBSC) study. J Public Health 2007, 15:179-186.

9. Cesario SK, Hughes LA: Precocious puberty: a comprehensive review of literature. JOGNN 2007, 36:263-274.

10. Mrug S, Elliott M, Gilliland MJ, Grunbaum JA, Tortolero SR, Cuccaro P, Schuster M: Positive parenting and early puberty in girls. Archives of Pediatrics and Adolescent Medicine 2008, 162:781-786.

11. Stice E, Presnell K, Bearman SK: Relation of early menarche to depression, eating disorders, substance abuse, and comorbid psychopathology among adolescent girls. Developmental Psychology 2001, 27:608-619.

12. Boyce W, Torsheim T, Currie C, Zambon A: The Family Affluence Scale as a measure of national wealth: validation of an adolescent self-reported measure. Social Indicators Research 2006, 78:473-487.

13. Haugland S, Wold B: Subjective health in adolescence - reliability and validity of survey methods. Journal of Adolescence 2001, 24:611-624.

14. Elgar F, Roberts C, Tudor-Smith C, Moore L: Validity of self-reported height and weight and predictors of bias in adolescents. Journal of Adolescent Health 2005, 37:371-375.

15. Ravens-Sieberer U, Erhart M, Torsheim T, et al: HBSC Positive Health Group An international scoring system for self-reported health complaints in adolescents. European Journal of Public Health 2008, 18:294-299.

16. Belsky J, Steinberg L, Draper P: Childhood experience, interpersonal development, and reproductive strategy: an evolutionary theory of socialization. Child Development 1991, 62:647-670.

17. Ellis BJ, Garber J: Psychosocial antecedents of variation in girls' pubertal timing: maternal depression, stepfather presence, and marital and family stress. Child Development 2000, 71:485-501.

18. Currie C, Molcho M, Boyce W, Holstein B, Torsheim T, Richter M: Researching health inequalities in adolescents: the development of the Health Behaviour in School-aged Children (HBSC) Family Affluence Scale. Soc Sci Med 2008, 66:1429-36.

19. Cole TJ, Belizzi MC, Flegal KM, Dietz WH: Establishing a standard definition for child overweight and obesity worldwide: international survey. BMJ 2000, 320:1240-3.

20. Cantril H: The pattern of human concern New Brunswick, NJ, Rutgers University Press 1965.

21. StataCorporation: Stata Statistical Software: Release 9 USA: TX CS 2005

22. Ong KK, Lynn Ahmed M, Dunger DB: Lessons from large population studies on timing and tempo of puberty (secular trends and relation to body size): the European trend. Molecular and Cellular Endocrinology 2006, 254-255:8-12. 
23. de La Rochebrochard E: Les âges à la puberté des filles et des garçons en France. [Boys and girls' ages at onset of puberty in France]. Population 1999, 54:933-962, French.

24. Irwin CE, Millstein SG: Biopsychological correlates of risk-taking behaviors during adolescence: can the physician intervene? Journal of Adolescent Health Care 1986, 7(Suppl):82-96.

25. Baumrind D: The influence of parenting style on adolescent competence and substance use. Journal of Early Adolescence 1991, 11:56-95.

26. Brown SA, McGue M, Maggs J, Schulenberg J, Hingson R, Swartzwelder S, Martin C, Chung T, Tapert SF, Sher K, Winters KC, Lowman C, Murphy S: A developmental perspective on alcohol and youths 16 to 20 years of age. Pediatrics 2008, 121(Suppl):290-310.

27. Caspi A, Lynam D, Moffitt TE, Silva PA: Unraveling girls' deliquency: biological, dispositional, and contextual contributions to adolescent misbehavior. Developmental Psychology 1993, 29:19-30

28. Graber JA, Lewinsohn PM, Seeley MS, Brooks-Gunn J: Is psychopathology associated with the timing of pubertal development? Journal of the American Academy of Child and Adolescent Psychiatry 1997, 36:1768-1776.

29. Johnston LD, O'Malley PM, Bachman JG: Monitoring the future: national survey results on drug abuse, 1975-2001. secondary school students Bethesda: National Institute on Drug Abuse, National Institutes of Health 2002, 1.

30. Goodson P, Evans A, Edmundson E: Female adolescents and onset of sexual intercourse: a theory-based review of research from 1984 to 1994. Journal of Adolescent Health 1997, 21:147-156.

31. Wellings K, Nanchahal K, Macdowall W, McManus S, Erens B, Mercer CH, Johnson AM, Copas AJ, Korovessis C, Fenton KA, Field J: Sexual behaviour in Britain: early heterosexual experience. Lancet 2001, 358:1843-50.

32. Kinsman S, Romer D, Furstenberg FF, Schwarz DF: Early sexual initiation: the role of peer norms. American Academy of Pediatrics 1998, 102:1185-1192.

33. Godeau E, Vignes C, Duclos M, Navarro F, Cayla F, Grandjean H: Facteurs associés à une initiation sexuelle précoce chez les filles: données françaises de l'enquête internationale Health behaviour in School-aged Children (HBSC)/OMS [factors associated with early sexual initiation in girls: French data from the international Health Behaviour in Schoolaged Children study/OMS]. Gynécologie Obstétrique et Fertilité 2008, 36:176-182.

34. Obesity: preventing and managing the global epidemic: report of a WHO consultation on obesity. WHO technical report series no. 894 Geneva: Wold Health Organization 2004.

35. Guo SS, Huang C, Maynard LM, Demerath E, Towne B, Chumlea WC, Siervogel RM: Body mass index during childhood, adolescence and young adulthood in relation to adult overweight and adiposity: the Fels Longitudinal Study. International Journal of Obesity Related MetabolicDisorders 2000, 24:1628-1635.

36. Engeland A, Bjørge T, Søgaard AJ, Tverdal A: Body mass index in adolescence in relation to total mortality: 32-year follow-up of 227000 Norwegian boys and girls. American Journal of Epidemiology 2003, 157:517-523.

37. Pierce $M B$, Leon $D A:$ Age at menarche and adult $B M I$ in the Aberdeen children of the 1950s cohort study. Am J Clin Nutr 2005, 82:733-9.

38. Dunger DB, Ahmed ML, Ong KK: Early and late weight gain and the timing of puberty. Moll Cell Endocrinol 2006, 65:1-8.

39. Coleman L, Coleman J: The measurement of puberty: a review. Journal of Adolescence 2002, 25:535-550.

40. Casey VA, Dwyer JT, Coleman KA, Krall EA, Gardner J, Valadian I: Accuracy of recall by middle-aged participants in a longitudinal study of their body size and indices of maturation earlier in life. Annals of Human Biology 1991, 18:155-166.

41. Downing J, Bellis MA: Early pubertal onset and its relationship with sexual risk taking, substance use and anti-social behaviour: a preliminary cross-sectional study. BMC Public Health 2009, 9:446.

\section{Pre-publication history}

The pre-publication history for this paper can be accessed here: http://www. biomedcentral.com/1471-2458/10/175/prepub

\section{doi:10.1186/1471-2458-10-175}

Cite this article as: Gaudineau et al.: Factors associated with early menarche: results from the French Health Behaviour in School-aged Children (HBSC) study. BMC Public Health 2010 10:175.

\section{Submit your next manuscript to BioMed Central and take full advantage of:}

- Convenient online submission

- Thorough peer review

- No space constraints or color figure charges

- Immediate publication on acceptance

- Inclusion in PubMed, CAS, Scopus and Google Scholar

- Research which is freely available for redistribution 